\title{
Numerical Investigation of Working Fluid Effect on Stirling Engine Performance
}

\author{
Sa'ed A. Musmar ${ }^{a}$, Iskander Tlili ${ }^{b, *}$ \\ ${ }^{a}$ Department of Industrial Engineering, Faculty of Engineering and Technology, University of Jordan, Amman, Jordan \\ ${ }^{b}$ Mechanical Engineering Department, Engineering College, Majmaah University, PO Box 66, Almajmaah, Saudi Arabia
}

\begin{abstract}
The Stirling engine is achieving great concern in the actual energy area since it has many advantages such as its cleanness and quietness. It is also considered a flexible prime mover for useful for several applications such as microcogeneration, solar thermal generation and other micro-distributed generation conditions. Theoretically, the Stirling cycle engine can efficiently convert heat into the mechanical work at the Carnot efficiency. The importance of the choice of working fluid is also demonstrated in the literature. In fact, the Stirling engine power can be increased ten times by changing the working fluid from air to hydrogen for example. This paper represents an evaluation of the on working fluid of a solar-dish Stirling heat engine. Thermal efficiency, exergetic efficiency and the rate of entropy generation corresponding to the optimum value of the output power are also evaluated. Numerical results demonstrate that the swept volume ratio is independent of the choice of working fluid.
\end{abstract}

Keywords: Stirling engine, Performance, Power, Efficiency, working fluid.

\section{Introduction}

Stirling engines are a type of external combustion engines that use different heat sources such as solar, bio-fuel, nuclear energy and so on [1-3]. Stirling engines operate in a closed cycle with a working fluid in gas state. Working fluid is circulated in two working spaces (compression and expansion) and three heat exchangers (cooler, heater and regenerator). The working space is divided into compression and expansion with two pistons namely displacer and power pistons (beta and gamma type Stirling engines). The displacer is used for distributing working gas between working spaces and the power piston is used for power production. In another type of Stirling engines called alpha Stirling, there are two separate expansion and compression spaces and two power pistons with no displacer. Very high potential for thermal efficiency along with other features such as quiet operation and compatibility with various sources of thermal energy has attracted researches around the world to implement them as power generators or refrigeration machines. In this regard, a precise thermal model

${ }^{*}$ Corresponding author. Tel.: +966509107698

Fax: +966164313714; E-mail: 1.tlili@mu.edu.sa

(C) 2015 International Association for Sharing Knowledge and Sustainability

DOI: $10.5383 /$ ijtee. 10.01 .005 is highly desired for predicting operation of Stirling engine with the lowest error and computational cost. Different thermal models of Stirling engines can be classified into empirical [4-8], analytical [9-16] and numerical [17-27] methods.

Among thermal methods, the most accurate models are the numerical ones. Some numerical models based on thermodynamic principles have been considered for analysis and performance prediction of Stirling engines. Urieli and Berchowitz [17] developed a numerical thermal model based on adiabatic expansion/compression processes. They substituted adiabatic expansion/compression processes instead of isothermal ones of early thermal models. Furthermore, they modified their ideal adiabatic model to a new model, so called simple analysis, in order to implements effect of non-ideal heat recovery of the regenerator, non-ideal heat transfer in the cooler and heater and pressure drops in heat exchangers [17]. Later, original simple analysis of Urieli and Berchowitz [17] was modified by a number of researchers [18-24] to include different loss mechanisms. Abbas et al. [18] developed a new analysis based on simple model where effects of non-ideal regeneration, shuttle loss and heat conduction losses were considered. Effects of pumping work loss and regenerator heat loss were evaluated in a 
research conducted by Strauss and Dobson [19]. Granodos et al. [20] and Nepveu et al. [21] developed a new model based on quasi-steady flow approach for analyzing an alpha type Stirling engine so-called the SOLO 161 Stirling engine. Parlak et al. [22] used quasi-steady flow analysis for performance prediction of a gamma-type Stirling engine. Tlili et al. [23] developed a secondorder quasi-steady mathematical model for evaluating performance of medium-temperature differential Stirling engines. In their analysis, effect of shuttle loss, heat and pressure losses were considered. Effect of gas spring hysteresis losses in the working spaces were studied by Tlili et al. [24]. In addition, they simultaneously analyzed the Stirling engine cycle considering a number of loss effects.

All researches concerning Stirling engine are so important, however, there was no sufficient data regarding the best working fluid of the Stirling engine, in this paper we develop a numerical model in order to calculate and evaluate the optimal working fluid for maximum power and efficiency.

A numerical simulation taking into account different thermal and mechanical losses was developed and tested using different Stirling engines data [15-17]. The results obtained were more realistic than those obtained by other models and correlated closely with the corresponding experimental data. Since this work is continuity for other previous work to determine the appropriate working fluid in addition to the prediction of the effect of these parameters on the engine performance in order to identify the optimal Thermodynamic parameters.

\section{Stirling Engine Classification}

\subsection{Operating principle}

To fulfill thermodynamic Stirling cycle, the engine included two volumes at different temperatures connected to each other through a regenerative heat exchanger and auxiliary heat exchangers.

Originally, Stirling engines were classified into groups according to their geometric configuration. In fact, there are three configuration systems: Alpha, Beta, and Gamma Fig. 1.
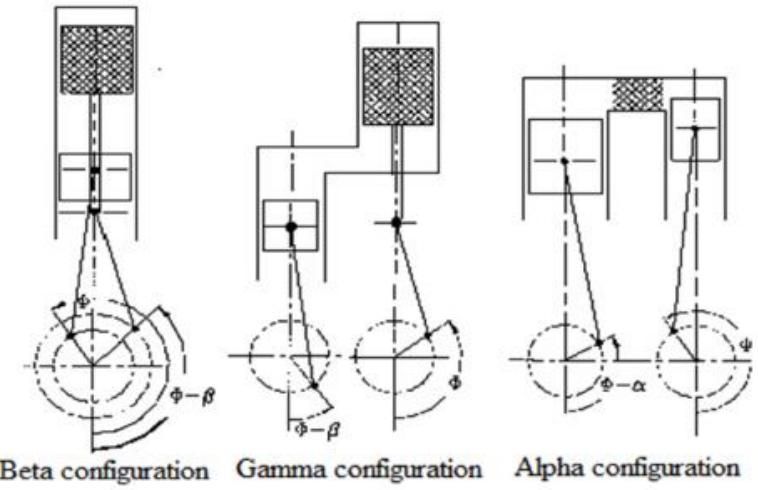

Alpha configuration

Fig. 1. Stirling engine configuration.

These terms described only the Stirling engine cylinder couplings that identified the way in which the displacer piston and the power piston were connected, with respect to the connection of the variable working spaces volume. These are the spaces inside the engine cylinder where the working fluid is heated and cooled respectively in a closed volume.

\subsection{The different configurations of Stirling engines}

The Beta engine [18] covers the group of Stirling engine using a single cylinder arrangement and where the displacer and the power piston are connected in tandem. The power is produced by the action of the pistons together. This configuration has sealing problems and loses its advantages compared to multi-cylinder engines.

The Gamma engine [19] is very similar to beta-type since the power output is produced in the same manner as in Beta engines. The only difference lies in the fact that the two pistons move in separate cylinders. The disadvantage of this configuration is the large dead space that it has.

The alpha engine [20] consists of two separate cylinders that each one has its own piston, either the displacer or the power piston and three heat exchangers. Each heat source is linked to its own cylinder. The power output is produced by the separate motion of the individual piston.

\section{Modeling}

\subsection{Analytic comparison for working fluid}

The characteristics of the various working fluids used in the Stirling engine (hydrogen, helium, air, carbon dioxide) were donated by Meijer (1970) [4] in the following table 1:

Table 1: Characteristics of the different working fluids

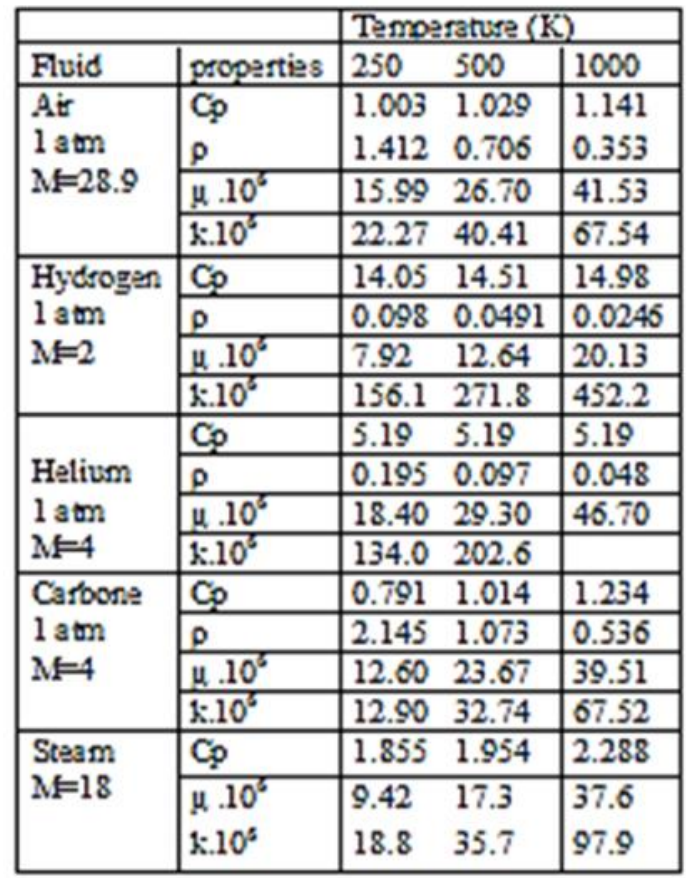

For Stirling engines, a gas is more efficient than another depending on its transport properties such as viscosity, thermal conductivity, specific heat, density.

The gas density is

$$
\rho=\frac{\mathrm{P} \mathrm{M}}{\mathrm{R} \mathrm{T}}
$$


The heat is transferred

$$
\mathrm{Q}=\mathrm{hA} \quad \mathrm{T}
$$

Nusselt number

$$
\mathrm{N}_{\mathrm{u}}=\mathrm{hk} / \mathrm{c}
$$

Reynolds number

$$
\mathrm{R}_{\mathrm{e}}=\rho \mathrm{ud} /
$$

The Nusselt number is related to the Reynolds number by the following equation

$$
\mathrm{N}_{\mathrm{u}}=\mathrm{BR}_{\mathrm{e}}^{\mathrm{q}}
$$

With B and $\mathrm{q}$ are constants that depend on the conditions of flow

From equations (3) (4) and (5) we will have:

$$
\text { h.k/c }=B(\rho u d /)^{\mathrm{q}}
$$

The best working fluid is that which combines a high heat transfer coefficient (h) with a friction loss in value more or less small $\left(\rho u^{2}\right)$.

To compare the working fluids are recommended to consider that the flow is steady; and the relationship between the friction factor and the Stanton number is given by the following equation:

$$
\mathrm{f} / 2=\mathrm{St}=\mathrm{h} / \rho \mathrm{cc}
$$

The variation of the fluid pressure is given by the following equation:

$$
\mathrm{P}=\frac{1}{\rho}\left(\frac{\mathrm{W}}{\mathrm{A}}\right)^{2} \frac{2 \mathrm{fL}}{\mathrm{d}}=\frac{1}{\rho}\left(\frac{\mathrm{W}}{\mathrm{A}}\right)^{2} \frac{\mathrm{fsL}}{2 \mathrm{~A}}
$$

Pumping power $\mathrm{p}$ is connected to $\Delta \mathrm{P}$ by the relation

$$
\mathrm{p}=\mathrm{W} \Delta \mathrm{P} / \rho \eta
$$

$\eta$ : Pumping efficiency

So

$$
P=\frac{1}{\eta} \frac{W}{\rho^{2}}\left(\frac{W}{A}\right)^{2} \frac{f s L}{2 A}=\frac{1}{\rho^{2}}\left(\frac{W}{A}\right)^{3} \frac{f s L}{2 \eta}
$$

The heat flux in the medium is:

$$
\mathrm{Q}=\mathrm{h}(\mathrm{sL}) \Delta \mathrm{T}
$$

So

$$
\frac{\mathrm{P}}{\mathrm{Q}}=\frac{1}{\eta} \frac{1}{\rho^{2}} \frac{(\mathrm{W} / \mathrm{A})^{3}(\mathrm{f} / 2) \mathrm{sL}}{\mathrm{h}(\mathrm{sL}) \mathrm{T}}
$$

According to equation (7)

$$
\frac{\mathrm{P}}{\mathrm{Q}}=\frac{1}{\eta} \frac{1}{\rho^{2}}\left(\frac{\mathrm{W}}{\mathrm{A}}\right)^{2} \frac{1}{\mathrm{c} T}
$$

Or

$$
\mathrm{W} / \mathrm{A}=\mathrm{Q} / \mathrm{c}\left(\mathrm{T}_{2}-\mathrm{T}_{1}\right) \mathrm{A}
$$

Substituting equation (12) in equation (13) found

$$
\frac{P}{Q}=\frac{Q^{2}}{\eta \rho^{2} c^{3} T\left(T_{2}-T_{1}\right)^{2} A^{2}}
$$

So

$$
\mathrm{Q}=\left(\eta \rho^{2} \mathrm{c}^{3} \mathrm{~T}\left(\mathrm{~T}_{2}-\mathrm{T}_{1}\right)^{2} \mathrm{~A}^{2}(\mathrm{P} / \mathrm{Q})^{1 / 2}\right)
$$

So for temperature and rate values $(\mathrm{P} / \mathrm{Q})$ we finally find:

$$
\mathrm{Q} \propto \sqrt{\left(\rho^{2} c^{3}\right)}
$$

And according to equation (1) we have

$$
\mathrm{Q} \propto \sqrt{\left(\mathrm{M}^{2} \mathrm{c}^{3}\right)}
$$

Considering the examples given in Table 1

$\begin{array}{ll}\text { Hydrogen } & \mathrm{Q}_{\mathrm{h}}: 104 \\ \text { Helium } & \mathrm{Q}_{\mathrm{he}}: 44 \\ \text { Steam } & \mathrm{Q}_{\mathrm{H}_{2} \mathrm{O}}: 44 \\ \text { Carbon dioxide } & \mathrm{Q}_{\mathrm{CO}_{2}}: 31 \\ \text { Air } & \mathrm{Q}_{\mathrm{A}}: 29\end{array}$

The coefficients of friction and heat transfer can be determined analytically only for laminar flow, and stationary in simple geometric shapes. For Stirling engines we used empirical relationships.

In the foregoing, it has not expressed the influence of temperature on the thermodynamic properties of the fluids. The dynamic viscosity varies more with temperature than the thermal conductivity and heat capacity $\mathrm{Cp}$. Therefore, the temperature range that interests us, just consider the variation of the thermal $\mu$ viscosity as a function of temperature (Figure.1) 


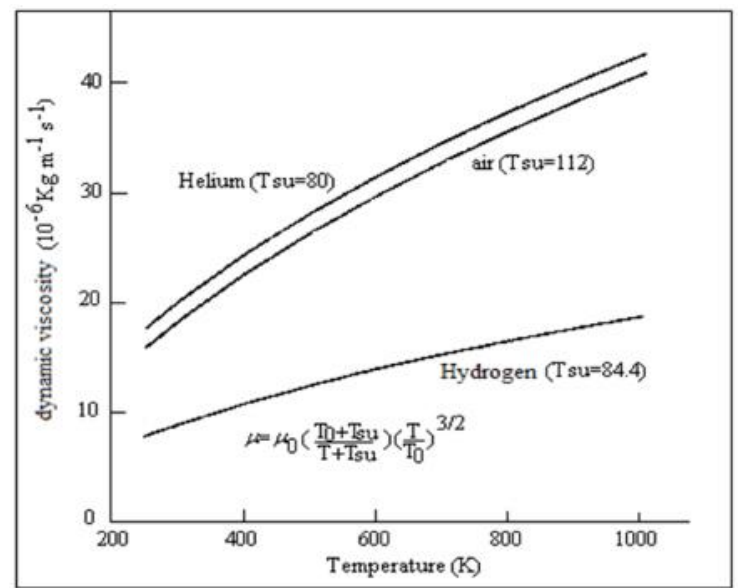

Fig. 2. Variation of the thermal.

\subsection{Coefficient of friction}

A suitable definition of friction factor is introduced by Ureili (1977), it is called Reynolds friction coefficient.

$$
\mathrm{f}_{\mathrm{r}}=\mathrm{F} \frac{\mathrm{d}^{2} \rho}{2 \mathrm{uv}}
$$

\section{With $\mathrm{F}$ friction force}

U mass flow density

On the other hand, the friction force is equal to the opposite of the pressing force $\mathrm{F}+\Delta \mathrm{pA}=0$

Which gives:

$$
p+\frac{2 f_{r} U V}{\operatorname{Ad}^{2} \rho}=0
$$

In equation (16) the sign of $\mathrm{u}$ is related to $\Delta \mathrm{p}$ sign. Once all the experimental values are known, it is easy to determine the friction coefficient fr.

The heater and cooler are both constituted by homogeneous packet of circular tubes. Table (2) has the coefficient of friction of Reynolds fr based on the Reynolds number for circular tubes. Note that the flow can be separated into three regimes: laminar flow ( $\operatorname{Re}<2000)$, a transitional regime $(2000<\operatorname{Re}<4000)$ and turbulent $(\operatorname{Re}>4000)$

Table 2: Friction and heat transfer coefficient for circular tubes

\begin{tabular}{|l|l|l|}
\hline Poiseuille & $\operatorname{Re}<2000$ & $\mathrm{f}_{\mathrm{r}}=16$ \\
\hline Transition & $2000<\operatorname{Re}<4000$ & $\mathrm{f}_{\mathrm{r}}=7.343 * 10^{-4} \mathrm{Re}^{1.3142}$ \\
\hline Blasius & $\operatorname{Re}>4000$ & $\mathrm{f}_{\mathrm{r}}=0.0791 \mathrm{Re}^{0.75}$ \\
\hline $\begin{array}{l}\text { Heat } \\
\text { transfer } \\
\text { coefficient }\end{array}$ & $\begin{array}{l}\text { reynolds Simple analogy }: \mathrm{St} \mathrm{Pr}=\mathrm{f}_{\mathrm{r}} /(2 \mathrm{Re}) \\
\text { So } \mathrm{h}=\mathrm{f}_{\mathrm{r}} \mu \mathrm{c}_{\mathrm{p}} /(2 \mathrm{dPr})\end{array}$ \\
\hline
\end{tabular}

In Fig. 2. it shows the friction factor and Reynolds also the product StPr depending on the Reynolds number for the flow in the regenerators.

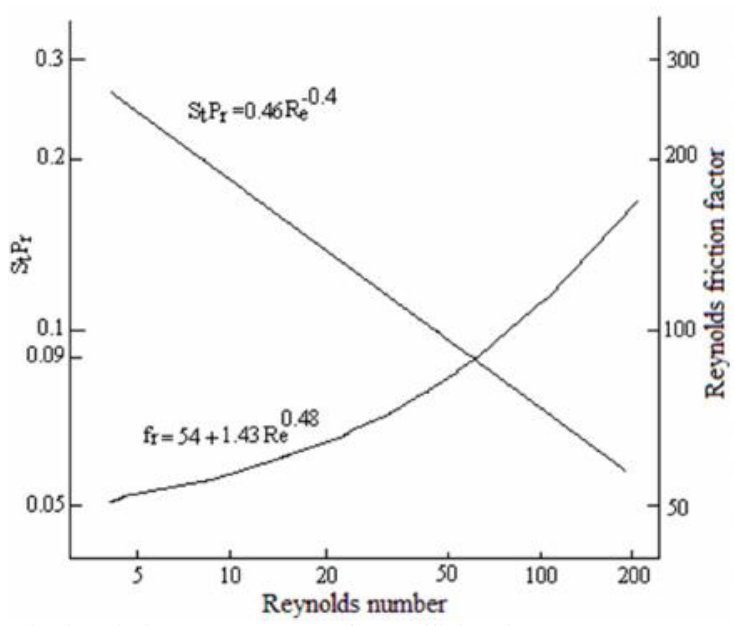

Fig. 3. Friction and heat transfer coefficient in regenerator

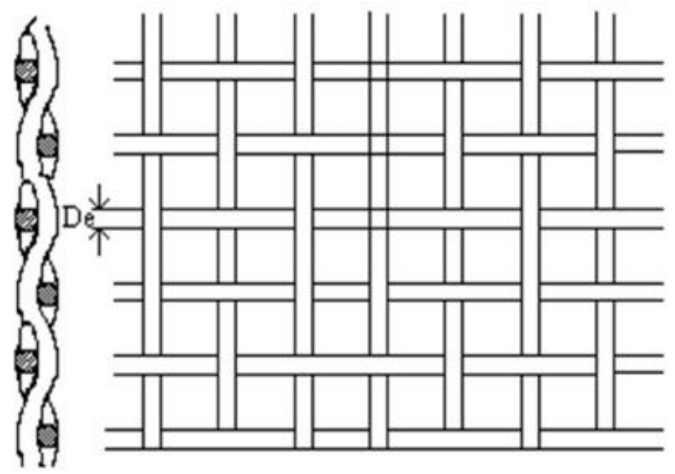

Fig. 4. Regenerator matrices

Where

$d_{m}$ - diameter of the wire.

$\mathrm{x}_{\mathrm{m}}$ - wire full length.

$\psi \quad$-porosity.

$\mathrm{v}_{\mathrm{m}}$ - Matrices volume du métal du grillage.

$\mathrm{v}$ - Empty volume.

$A_{m}-$ Wet surface.

d - hydraulics diameter.

Since $: \mathrm{v}_{\mathrm{m}}=\frac{\pi \mathrm{d}_{\mathrm{m}}{ }^{2} \mathrm{x}_{\mathrm{m}}}{4}$ and $\quad \mathrm{A}_{\mathrm{m}}=\pi \mathrm{d}_{\mathrm{m}} \mathrm{x}_{\mathrm{m}}$

So $: \mathrm{v}_{\mathrm{m}}=\frac{d_{m} A_{m}}{4}$

and : $\psi=\frac{\mathrm{V}}{\mathrm{V}+\mathrm{V}_{\mathrm{m}}} \quad ; \mathrm{d}=\frac{4 \mathrm{~V}}{\mathrm{~A}_{\mathrm{m}}}$

So $\mathrm{d}=\frac{d_{m} \Psi}{1-\Psi}$. 
Table 3: Matrices used in the regenerators

\begin{tabular}{|l|l|l|}
\hline & GM GPU-3 & Ford 4-215 \\
\hline Wire length $\left(\mathrm{in}^{-1}\right)$ & 200 & 200 \\
\hline Wire diameter $\mathrm{d}_{\mathrm{m}}(\mathrm{mm})$ & 0.04 & 0.036 \\
\hline Porosity $\psi$ & 0.697 & 0.618 \\
\hline
\end{tabular}

\subsection{Regenerator temperature}

The temperature in real regenerator is almost linear profile [30] and therefore it is assumed that the ideal regenerator has a linear temperature profile between the temperature $T_{f}$ of the cooler and the heater $\mathrm{T}_{\mathrm{h}}$, So:

$T(x)=\left(T_{h}-T_{f}\right) x / L_{r}+T_{f}$

Where $\mathrm{L}_{\mathrm{r}}$ regenerator length

The mass of gas in the regenerator $\mathrm{m}_{\mathrm{r}}$ is given by:

$$
\mathrm{m}_{\mathrm{r}}=\int_{0}^{\mathrm{v}_{\mathrm{r}}} \rho d \mathrm{v}_{\mathrm{r}}
$$

Where $\rho$ density

$\mathrm{dv}_{\mathrm{r}}=\mathrm{A}_{\mathrm{r}} \mathrm{dx}$

For a surface of constant flow was $A_{r}$ so $V_{r}=A_{r} L_{r}$ Apply ideal gas $\mathrm{P}=\rho \mathrm{r} \mathrm{T}$ in the equation (12) we have:

$$
\mathrm{m}_{\mathrm{r}}=\frac{\mathrm{V}_{\mathrm{r}} \mathrm{p}}{\mathrm{R}} \int_{0}^{\mathrm{L}_{\mathrm{r}}} \frac{1}{\left[\left(\mathrm{~T}_{\mathrm{h}}-\mathrm{T}_{\mathrm{f}}\right) \mathrm{x}+\mathrm{T}_{\mathrm{f}} \mathrm{L}_{\mathrm{r}}\right]} \mathrm{dx}
$$

The integral of the right side of equation (13) and simplifying we find:

$$
m_{r}=\frac{V_{r} p}{R} \frac{\ln \left(T_{h} / T_{f}\right)}{\left(T_{h}-T_{f}\right)}
$$

We define the average effective regenerator temperature $\mathrm{Tr}$ in terms of the ideal gas equation of state:

$$
m_{r}=V_{r} p /\left(R T_{r}\right)
$$

Comparing equations (14) and (15) we obtained:

$$
T_{r}=\left(T_{h}-T_{f}\right) / \ln \left(T_{h} / T_{f}\right)
$$

\section{Results and Discussion}

\subsection{Effect of working fluid}

The choice of the working fluid is very important as shown in Fig 4, 5 and 6 as is demonstrated in the analytical part. We can increase the power of a Stirling engine of ten times through change air to the hydrogen as working fluid.

It is found that hydrogen is the most efficient for improving the power, then helium and air. Nevertheless, the problem is that hydrogen involves risks inflammation unless there are technical solutions. Helium is thus more advantageous than the other gases.

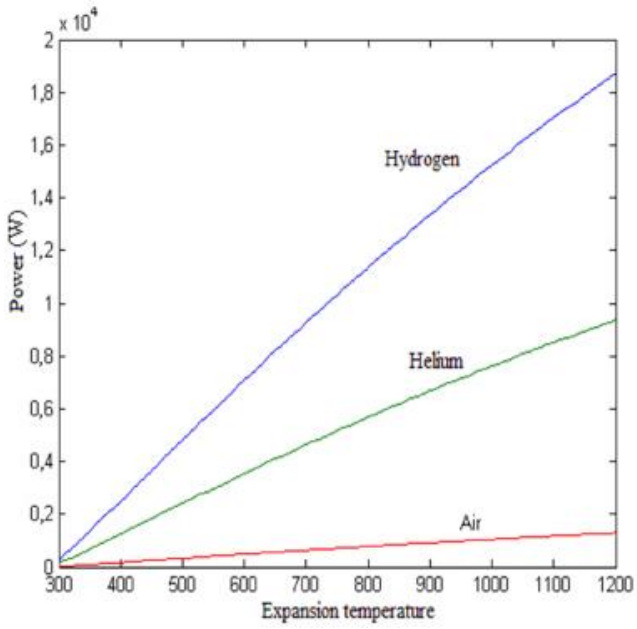

Fig. 5. Effect of the working fluid on the engine power to different expansion temperatures

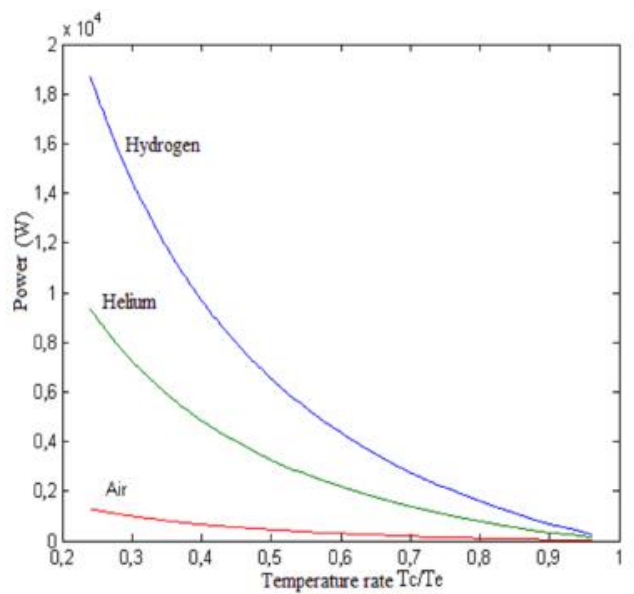

Fig. 6. Variation of power as a function of the temperature rate

Fig 6 shows that the choice of the swept volume ratio is very important to increase the power; the value of the swept volume ratio is independent of the choice of working fluid.

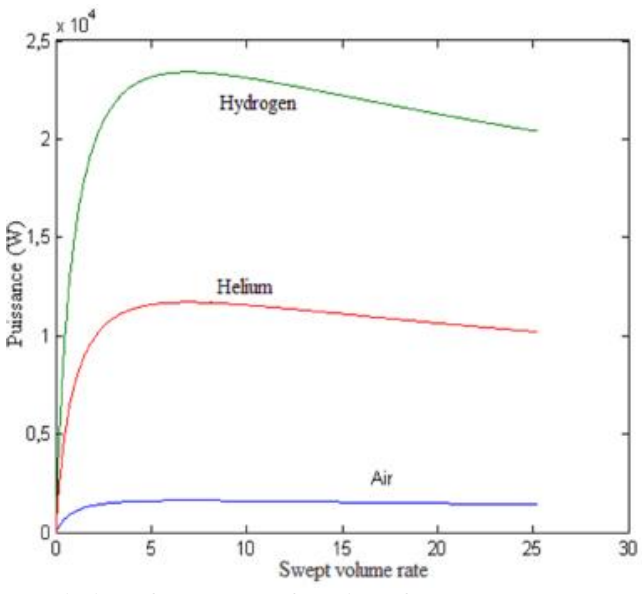

Fig. 7. Variation of power as a function of the swept volume rate 


\section{Conclusion}

Although Stirling engine has different advantage compared to other engine and especially for environmental purpose. This kind of engine was not studied enough and effectively, that's why this study was conducted in order to analyze the engine function and identify the most significant parameter affecting its performance.

The numerical model developed and validated with other Stirling engine was applied to different Stirling engine and tested with various thermodynamic parameters. But unfortunately without taking in account the effect of working fluid, for these reasons this wok start a numerical investigation of working fluid effect on Stirling engine performance

The following conclusions drawn from this study are:

- The regenerator is responsible of the undesirable pressure decrease and all high thermal losses, it remains the most significant compartment of the Stirling engine and an appropriate working fluid can reduce all this irreversibilities.

- The engine performance depends critically on the working flow

- Results from this study indicate that the engine performance will increase with the increase of the heater temperature, the heat input, the regenerator heat transfer which is strongly related to the appropriate working fluid

- At a working fluid mass equal to $1 \mathrm{~g}$, the engine power increases and the engine efficiency reaches a maximum of about $42 \%$ in case of GPU-3.

- The engine performance should be increased if better working fluid e.g. helium or hydrogen is used instead of air.

\section{References}

[1] Campos M. C., Vargas J. V. C., Ordonez J. C., Thermodynamic optimization of a Stirling engine, Energy 44 (2012): 902-910.

[2] Costa S. C., Barrutia H., Esnaola J. A., Tutar M., Numerical study of the pressure drop phenomena in wound woven wire matrix of a Stirling regenerator, Energy Conversion and Management 67(2013): 57-65.

[3] Sanchez D., Chacartegui R., Torres M., Sanchez T. Stirling based fuel cell hybrid systems: An alternative for molten carbonate fuel cell. Journal of Power Sources 2009; 192: 621 84-93.

[4] I Tlili, Y Timoumi, and S B Nasrallah: "Numerical simulation and losses in a Stirling engine" Heat and Technology Vol.24,n. 1, pp.97-105, 2006.

[5] Kongtragool B., Wongwises S., Investigation on power output of the gamma configuration low temperature differential Stirling engines. Renewable Energy, 30 (2005):465-476

[6] Tlili I., Sa'ed A. Musmar, 'Thermodynamic evaluation of a second order simulation for Yoke Ross Stirling engine' Energy Conversion and Management, Volume 68, April 2013, Pages 149-160.

[7] I Tlili, Y Timoumi, and S B Nasrallah: "Thermodynamic analysis of the Stirling heat engine with regenerative losses and internal irreversibilities" Int. J. Engine Research. Vol. 9,pp 45-56, 2007.
[8] Prieto J. I., González M. A., González C., Fano J., A new equation 635 representing the performance of kinematic Stirling engines. Proceedings of the Institution of Mechanical Engineers, Part C: Journal of Mechanical Engineering Science, 214 (2000):449-464

[9] Yaqi L., Yaling H., Weiwei W., Optimization of solarpowered Stirling heat engine with finite-time thermodynamic. Renewable Energy 36(2011): 421-427.

[10] Y Timoumi, I Tlili, S B Nasrallah:"Performance optimization of Stirling engines" Renewable Energy, 33 (2008) :2134-2144.

[11] Petrescu S., Costea M., Harman C., Florea T., Application of the direct method to irreversible Stirling cycles with finite speed. International Journal of Energy Research 26 (2002): 589-609.

[12] Costea M., Petrescu S, Harman C., The effect of irreversibilities on solar Stirling engine cycle performance, Energy Conversion and Management 40(1999):1723-1731.

[13] Y Timoumi, I Tlili, S B Nasrallah: "Design and performance optimization of GPU-3 Stirling engines" Energy 33 (2008) 1100-1114.

[14] Walker G., Stirling Engines. Clarendon Press, Oxford, 1980

[15] I Tlili, "Thermodynamic Study On Optimal Solar Stirling Engine Cycle Taking Into Account The Irreversibilities Effects” Energy Procedia, Volume 14, 2012, Pages 584591.

[16] Martini W.R., Stirling Engine Design Manual. Arch, DOE/656 NASA/3152-78/1 NASA CR-135382, April 1978 .

[17] Urieli I., Berchowitz D.M., Stirling Cycle Engine Analysis, Adam Hilger LTD, Bristol, 1984.

[18] Sa'ed A Musmar, AT Al-Halhouli, Iskander Tlili, S Büttgenbach. 'Performance Analysis of a New Water Based Micro-Cooling System, Experimental Heat Transfer, DOI:10.1080/08916152.2015.1024353, May 2015.

[19] Strauss J.M., Dobson R.T., Evaluation of a second order simulation for Stirling engine design and optimisation Journal of Energy in Southern Africa, 21 (2010):17-29.

[20] Y Timoumi, I Tlili and S B Nasrallah: "Reduction of energy losses in a Stirling engine" Heat and technology Vol, 25, n. 1, pp 84-93, 2007.

[21] Nepveu F., Ferriere A., Bataille F., Thermal model of a dish/Stirling system. Solar Energy, 83 (2009):81-89.

[22] Parlak N., Wagner A., Elsner M., Soyhan H. S., Thermodynamic analysis of a gamma type Stirling engine in non-ideal adiabatic conditions. Renewable Energy, 34 (2009): 266-273.

[23] Tlili I., Timoumi Y., Nasrallah S. B., Analysis and design consideration of mean temperature differential Stirling engine for solar application. Renewable Energy, 33 (2008):1911-1921.

[24] Tlili I., Finite time thermodynamic evaluation of endoreversible Stirling heat engine at maximum power conditions. Renewable and Sustainable Energy Reviews, Volume 16, Issue 4, May 2012, Pages 2234-2241. 